\title{
Adhesion to nematodes of conidia from the nematophagous fungus Drechmeria coniospora
}

\author{
HANS-BöRJE JANSSON* \\ Department of Microbial Ecology, Lund University, Ecology Building, Helgonavägen 5, S-223 62 Lund, Sweden
}

(Received 27 November 1992; revised 19 February 1993; accepted 16 March 1993)

\begin{abstract}
Conidia of the endoparasitic nematophagous fungus Drechmeria coniospora adhere to the sensory organs of many nematode species. In some cases the adhesion phase is followed by penetration of the nematode cuticle and subsequent infection. In a study of eight different nematode species and five strains of the fungus only two species were infected: Panagrellus redivivus was infected by all strains and Ditylenchus dipsaci was infected by four strains, although the conidia of all fungal strains adhered to all of the nematode species tested. Treatment of the nematode $\boldsymbol{P}$. redivivus and the conidia of $\boldsymbol{D}$. coniospora with proteases gave a decreased adhesion in contrast to glycosidases, lipases and other enzymes tested. Inhibitory effects on adhesion were obtained after treatment of conidia with the carbohydrate $\mathrm{N}$-acetylneuraminic acid and the amino acids alanine and proline. Hydrophobicity and electrical charge appear not to be involved in conidial adhesion. A previous hypothesis on the presence of a sialic-acid-specific lectin in this interaction appears to be incorrect and the present results indicate no involvement of carbohydrates in the adhesion process. The results suggest that the adhesion is mediated by protein(s) in the adhesive part of the conidium binding to protein(s) excreted from the sensory organs of the nematodes.
\end{abstract}

\section{Introduction}

Conidia of the endoparasitic nematophagous fungus Drechmeria coniospora adhere to the cuticle of many nematode species (Jansson \& Nordbring-Hertz; 1983; Jansson et al., 1985). After conidial adhesion the fungus may produce a germ tube which penetrates the nematode cuticle, and infects and digests the animals (Jansson et al., 1984; Dijksterhuis et al., 1990). After a maturation phase, the conidia form an adhesive bud helping them to stick to the nematode surface. The adhesive can be visualized by electron microscopy and has been suggested to contain carbohydrate moieties as shown by staining with ruthenium red (Saikawa, 1982).

Most work on this interaction has been performed using the bacteriovorous nematode Panagrellus redivivus. With this nematode, the conidia adhere exclusively to the chemosensory structures in the head of males, females and juveniles, and in the tail of male specimens (Jansson \& Nordbring-Hertz, 1983). This adhesion pattern was suggested to be due to the presence of a sialic-acidspecific lectin located on the adhesive bud of the conidia binding to sialic acid residues located at the surface of the sensory organs of $P$. redivivus (Jansson \& NordbringHertz, 1983, 1984). However, recent studies have

\footnotetext{
*Tel. (46) 109614; fax (46) 104158; e-mail HBJ@castor.ldc.lu.se.
}

suggested that sialic acids may not exist on, or be synthesized by, this nematode (Jansson et al., 1986; Bacic et al., 1990; Reuter et al., 1991). This discrepancy between biological inhibition experiments and chemical analyses therefore warranted a reinvestigation of the specificity involved in the interaction between nematodes and $D$. coniospora. In addition, in the present investigation other possible interaction mechanisms, such as hydrophobicity and electrical charge, were studied. The strain of the fungus used in the previous studies has partially lost its ability to infect nematodes, and attempts to restore this ability have not been successful (Zuckerman et al., 1989). New fungal strains have therefore been tested in this study.

\section{Methods}

Fungal strains. Five strains of Drechmeria coniospora (Drechsler) W. Gams \& Jansson were used: strain (1) was isolated from Danish soils and was the one previously used by the present author (CBS 615.82); strain (2) was isolated in Germany; strain (3) in England; strain (4) in Canada; and strain (5) was isolated in Lund, Sweden by the present author in 1990. All strains were grown on diluted corn meal agar (CMA 1:10) and the conidia were harvested by flooding the plates with a small volume of sterile distilled water as described previously (Jansson \& Nordbring-Hertz, 1983).

Nematodes. The bacteriovorous nematode Panagrellus redivivus was cultivated axenically as described by Jansson \& Nordbring-Hertz (1979). The plant-parasitic nematodes (Ditylenchus dipsaci, Ditylenchus 
destructor, Pratylenchus penetrans and Cephalenchus sp.) were grown monoxenically on callus cultures. The beet cyst nematode Heterodera schachtii was cultivated monoxenically on roots. The animal-parasitic nematodes, Ostertagia ostertagi and $O$. quadrospinulatum, were obtained from infected animals.

Adhesion assay. To study the adhesion of conidia to nematodes and the subsequent infection, a conidial suspension (about $10^{9} \mathrm{ml}^{-1}$ ) in water or in appropriate buffer was spread onto a water-agar plate and about 500 nematodes were added to the plate. After $1-2 \mathrm{~h}$ the nematodes were collected, stained with lactophenol blue and observed under the microscope. Nematodes, with and without adhering conidia, were counted and the percentage of nematodes with adhering conidia was calculated. A total of 100-200 nematodes was counted for each category. Each experiment was repeated two to six times and the final results are presented as a percentage of the controls $(100 \%)$. Some unstained nematodes were left on the water-agar plates and observed for infection after 3-5 d.

Inhibition studies. Inhibition of adhesion was studied after various types of treatments of conidia and/or nematodes as follows. (i) Conidia were treated with $50 \mathrm{~mm}$-carbohydrate solutions (see Table 2) and $50 \mathrm{~mm}$ solutions of proline and alanine in $10 \mathrm{~mm}$-buffer (MOPS, $\mathrm{pH} 7.2$ ) for $24 \mathrm{~h}$ at room temperature. There was no germination of conidia during this incubation period. The conidia were then washed in buffer and added to water-agar plates. The adhesion assay was done as described above and the inhibitory effect of carbohydrates and amino acids on adhesion was calculated.

(ii) Conidia were treated with $\mathrm{NaCl}, \mathrm{LiCl}, \mathrm{MgSO}_{4}$ and $\mathrm{CaCl}_{2}$ at concentrations from $0.001 \mathrm{M}$ to $5 \mathrm{M}$ for $24 \mathrm{~h}$ at room temperature. The adhesion assay was done as above using the treated conidia without subsequent washing and the effects of ionic strength were studied.

(iii) The effects of $\mathrm{pH}$ were investigated after treatment of the conidia with $10 \mathrm{~mm}$ Universal buffer, pH 2-12 (Perrin \& Dempsey, 1974) for $24 \mathrm{~h}$ at room temperature. The treated conidia were used unwashed and the adhesion was studied as above.

(iv) The effects on adhesion and infection were also studied after treatment of nematodes ( $P$. redivivus) and conidia with different enzymes in $10 \mathrm{~mm}$ buffer for $1 \mathrm{~h}$ at $37^{\circ} \mathrm{C}$ for conidia and $30^{\circ} \mathrm{C}$ for nematodes unless otherwise stated: Pronase E (Merck), 700 units $\mathrm{ml}^{-1}$

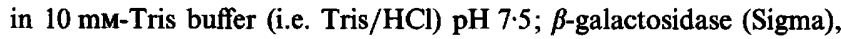
400 units $\mathrm{ml}^{-1}$ in $10 \mathrm{~mm}$-Tris buffer $\mathrm{pH} \mathrm{7.2;} \mathrm{lipase} \mathrm{(Sigma),}$

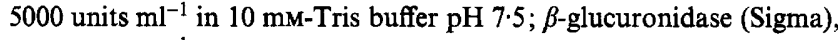
2000 units $\mathrm{ml}^{-1}$ in $10 \mathrm{mM}$-Tris buffer $\mathrm{pH} \mathrm{7.2;} \mathrm{L-fucose} \mathrm{dehydrogenase}$ (Sigma), 8 units $\mathrm{ml}^{-1}$ in $10 \mathrm{~mm}$-Tris buffer $\mathrm{pH} 8.7$; L-amino acid oxidase (Sigma), 2 units $\mathrm{ml}^{-1}$ in $10 \mathrm{~mm}$-Tris buffer $\mathrm{pH} \mathrm{6.5}$; L-lysine decarboxylase (Sigma), 6.5 units $\mathrm{ml}^{-1}$ in $10 \mathrm{mM}$-Tris buffer $\mathrm{pH} 6.0 ; \beta$-glucosidase (Sigma), 300 units $\mathrm{ml}^{-1}$ in $10 \mathrm{~mm}$-sodium acetate buffer $\mathrm{pH} \mathrm{5.0; \alpha -}$ glucosidase (Sigma), 120 units ml $^{-1}$ in $10 \mathrm{~mm}$-Tris buffer $\mathrm{pH} 6.5,25^{\circ} \mathrm{C}$; collagenase (Ega-Chemie), $10 \mathrm{mg} \mathrm{ml}^{-1}$ in $10 \mathrm{mM}$-Tris buffer $\mathrm{pH} 7 \cdot 2$, $25^{\circ} \mathrm{C}$; neuraminidase (Sigma), 10 units $\mathrm{ml}^{-1}$ in $10 \mathrm{mM}$-sodium acetate

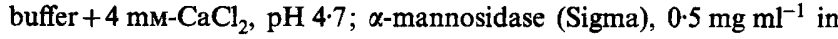
$10 \mathrm{~mm}$-sodium acetate buffer $\mathrm{pH} 4.5,25^{\circ} \mathrm{C}$; trypsin (Sigma) $10 \mathrm{mg} \mathrm{ml}^{-1}$ in $10 \mathrm{~mm}$-Tris buffer $\mathrm{pH} 7 \cdot 5,25^{\circ} \mathrm{C}$; endoglycosidase $\mathrm{F}-\mathrm{N}$ glycosidase $\mathrm{F}$ (Sigma), $2 \mathrm{U} \mathrm{ml}^{-1}$ in $10 \mathrm{mM}$-Tris buffer, $\mathrm{pH} 7 \cdot 2,30^{\circ} \mathrm{C}$. Controls were done with heat-denatured enzymes $\left(15 \mathrm{~min}, 95^{\circ} \mathrm{C}\right)$. After washing in appropriate buffers the adhesion assay was done as described above.

Hydrophobic interactions and electrical charge studies. Unisphere polystyrene particles (Serva) no. 20 and 22 of diameter 0.5 and $0.8 \mu \mathrm{m}$, respectively, were examined for their capacity to bind to conidia. These particles are hydrophobic and have been used for studies of hydrophobic interactions of micro-organisms (Hazen \& Hazen, 1987). Other Unisphere particles that were used were carboxylated (no. 23, diameter $0.8 \mu \mathrm{m}$ ). The attachment of polystyrene beads to conidia was investigated in the following manner. Solutions $(10 \mu \mathrm{l})$ of the Unisphere particles were mixed with $2 \mathrm{ml}$ cold $50 \mathrm{~mm}$-potassium phosphate buffer $\mathrm{pH} 7 \cdot 2$, and $200 \mu \mathrm{l}$ of this solution was mixed with $100 \mu \mathrm{l}$ of a conidial suspension in the same buffer. After $2 \mathrm{~min}$ the mixture was vortexed for $30 \mathrm{~s}$ and the adhesion of particles to the conidia was examined under the microscope.

To investigate possible involvement of electrical charge in the adhesion process, ion-exchange chromatography beads were used (Pendland \& Boucias, 1991). Bio-Rad CM (negatively charged) and Bio-Rad DEAE (positively charged) were washed in $10 \mathrm{~mm}-$ MOPS buffer ( $\mathrm{pH} 7 \cdot 2$ ), diluted 20 times and mixed with a conidial suspension. After $30 \mathrm{~min}$ the attachment of conidia to the beads was examined under the microscope.

Staining. Labelling of proteinaceous material on nematodes and conidia was done with $0.2 \%$ Coomassie Brilliant Blue G-250 in $40 \%$ methanol and $10 \%$ acetic acid according to Premachandran et al. (1988), after which the organisms were observed microscopically.

\section{Results}

\section{Host specificity}

The conidia of the five strains of $D$. coniospora adhered to all nematode species tested. The adhesion did not necessarily lead to penetration and infection of the nematode, and only two nematode species became infected, $P$. redivivus by all five strains, and $D$. dipsaci by all but the previously used fungal strain no. 1 . The two Ditylenchus species behaved differently in that the conidia adhered to both $D$. dipsaci and $D$. destructor, but only $D$. dipsaci was infected. The two animal parasitic nematodes, $O$. ostertag $i$ and $O$. quadrospinulatum, tested as third stage juveniles and characterized by the presence of an extra cuticle from the previous moult, were also not infected. As far as infection is concerned, there appears to be a high host specificity within the fungal species, but little difference between the strains tested. Therefore, the new strain (no. 5) was used in the following experiments.

\section{Inhibition of adhesion by carbohydrates}

When conidia of $D$. coniospora strain (5) were treated with 20 carbohydrates followed by adhesion experiments using the nematode $P$. redivivus only the sialic acid, $N$ acetylneuraminic acid, reduced adhesion of the conidia (Table 1). Similar results were also obtained when the other strains of the fungus were studied. The exception was strain (1), which had been subjected to prolonged axenic growth in the laboratory, and which showed a very high variation in the results of inhibition studies (data not shown).

\section{Negative charge and hydrophobicity}

Polystyrene beads (Unisphere latex particles, $0.5 \mu \mathrm{m}$ diameter) adhered to the entire surface of the conidia (Table 2). Larger beads $(0.8 \mu \mathrm{m})$ did not adhere to the 
Table 1. Effects of carbohydrate treatment of conidia of $D$. coniospora on adhesion to $P$. redivivus

\begin{tabular}{|c|c|c|}
\hline Carbohydrate & Mean* $\pm \operatorname{SE}(n)$ & $P \dagger$ \\
\hline $\mathrm{N}$-Acetylneuraminic acid & $55 \cdot 7 \pm 7 \cdot 2(3)$ & $P<0.001$ \\
\hline Glucose & $97.1 \pm 10.6(2)$ & NS \\
\hline Galactose & $88.5 \pm 5.9(2)$ & NS \\
\hline Fructose & $85 \cdot 6 \pm 10 \cdot 3(2)$ & NS \\
\hline Mannose & $95.8 \pm 9.7(2)$ & NS \\
\hline Arabinose & $100 \cdot 2 \pm 0.5(2)$ & NS \\
\hline Fucose & $96.3 \pm 9.6(2)$ & NS \\
\hline Sorbose & $92 \cdot 2 \pm 17 \cdot 2(2)$ & NS \\
\hline Lactose & $86.0 \pm 5 \cdot 6(2)$ & NS \\
\hline Melibiose & $87.5 \pm 9.3(2)$ & NS \\
\hline Xylose & $99 \cdot 0 \pm 1.0(2)$ & NS \\
\hline 2-Deoxyglucose & $85.4 \pm 8.8(2)$ & NS \\
\hline 2-Deoxygalactose & $83 \cdot 6 \pm 6 \cdot 2(2)$ & NS \\
\hline Methyl glucopyranose & $96 \cdot 3 \pm 6.0(2)$ & NS \\
\hline Methyl mannoside & $99.8 \pm 7.9(2)$ & NS \\
\hline Glucose phosphate & $84 \cdot 5 \pm 2 \cdot 7(3)$ & NS \\
\hline Glucosamine hydrochloride & $93 \cdot 3 \pm 10 \cdot 3(2)$ & NS \\
\hline$N$-Acetylglucosamine & $93 \cdot 5 \pm 2 \cdot 1(2)$ & NS \\
\hline $\mathrm{N}$-Acetylgalactosamine & $103 \cdot 3 \pm 2 \cdot 0(2)$ & NS \\
\hline $\mathrm{N}$-Acetylmannosamine & $91 \cdot 7 \pm 5 \cdot 3(2)$ & NS \\
\hline
\end{tabular}

* Fraction of nematodes with adhering conidia in percentage of controls $(100 \%)$.

$\dagger \chi^{2}$-test, compared with controls $(100 \%)$.

NS, Not significant.

Table 2. Attachment of polystyrene beads, with and without carboxyl groups, to conidia of D. coniospora

\begin{tabular}{|c|c|c|c|c|}
\hline \multirow[b]{2}{*}{ Effect } & \multicolumn{2}{|c|}{ Polystyrene beads } & \multicolumn{2}{|c|}{$\begin{array}{l}\text { Polystyrene beads } \\
\text { with carboxyl } \\
\text { groups }\end{array}$} \\
\hline & Mean* $\pm S E$ & $\% \dagger$ & Mean* \pm SE & $\% \dagger$ \\
\hline $\begin{array}{l}\text { Beads adhering only to } \\
\text { adhesive buds }\end{array}$ & $30 \cdot 3 \pm 2 \cdot 6$ & $17 \cdot 3$ & $127 \cdot 0 \pm 7 \cdot 7$ & $62 \cdot 9$ \\
\hline $\begin{array}{l}\text { Beads adhering to entire } \\
\text { conidium }\end{array}$ & $139 \cdot 7 \pm 11 \cdot 7$ & $80-0$ & $40 \cdot 0 \pm 0 \cdot 8$ & $19 \cdot 9$ \\
\hline No beads attached & $4 \cdot 7 \pm 2 \cdot 7$ & $2 \cdot 7$ & $35 \cdot 0 \pm 5 \cdot 3$ & $17 \cdot 3$ \\
\hline
\end{tabular}

* Number of conidia with adhering beads; mean of three replicates. $\dagger$ Percentage of total number of conidia counted.

conidia. Since the hydrophobicity of the polystyrene beads is inversely proportional to the size (Hazen \& Hazen, 1987), it thus appears that the conidia are moderately hydrophobic. Polystyrene beads with carboxyl groups adhered mainly to the adhesive buds of the conidia (Table 2), suggesting the involvement of another factor, e.g. the carboxyl group, in the adhesion mechanism.

To study the possible involvement of charges on the conidia in the adhesion process, ion-exchange gels were used. Bio-Rad CM chromatography gels have a high negative charge density and the conidia did not interact at all with this gel, indicating that positive charge was not involved. Positively charged beads (Bio-Rad DEAE) bound the conidia (both adhesive buds and conidial surface) to the beads (Fig. 1a), demonstrating a negative charge on the entire conidial surface.

When the different beads, both polystyrene and ionexchange beads, were tested on the nematode $P$. redivivus no binding of the beads was apparent.

\section{Effects of ionic strength, $p H$ and amino acids}

Treatment of the conidia with different salts prior to adhesion experiments resulted in various effects depending on the type of ion used. $\mathrm{NaCl}$ and $\mathrm{LiCl}$ had no effect on adhesion, even at a concentration of $5 \mathrm{M}$ (Fig. 2). Inhibition of adhesion resulted after treatment with $\mathrm{MgSO}_{4}$ and $\mathrm{CaCl}_{2}$. There were no obvious differences resulting from the different anions $\left(\mathrm{Cl}^{-}\right.$and $\left.\mathrm{SO}_{4}^{2-}\right)$ used, as judged by substitution experiments, and the results suggest that the inhibition of adhesion was due to the divalent cations $\left(\mathrm{Mg}^{2+}\right.$ and $\left.\mathrm{Ca}^{2+}\right)$ used.

The effect of $\mathrm{pH}$ was tested after treatment of the conidia with the buffer solutions and a pronounced inhibition of adhesion was shown at $\mathrm{pH} \mathrm{2-6}$ and $\mathrm{pH}$ 8-12 (Fig. 3). At pH 7 adhesion was similar to that in unbuffered controls in distilled water.

The effects on adhesion after treatment of the conidia with the amino acids proline and alanine, and the sialic acid $\mathrm{N}$-acetylneuraminic acid, were tested at two $\mathrm{pH}$ values, 2 and 7 . All three compounds caused some inhibition of adhesion at both $\mathrm{pH}$ values (Fig. 4), indicating the possible importance of carboxyl and/or amino groups in the adhesion process.

\section{Enzymic treatment}

When $P$. redivivus was treated with different enzymes, only the proteolytic enzymes Pronase E and trypsin had an inhibitory effect on adhesion of $D$. coniospora conidia (Table 3). When the nematodes were stained with the protein stain Coomassie Brilliant Blue, the main staining occurred around the pores of the sensory structures of the nematodes. Both amphids and inner labial papillae in the head region (Fig. $1 b$ ) and caudal papillae in the male tail (Fig. 1c) were labelled together with exudates from these organs.

When the conidia were treated with the different enzymes only Pronase E reduced adhesion to the nematode surface (Table 4). Trypsin also reduced adhesion, but in this case the denatured enzyme had a similar effect. Both active and denatured mannosidase appeared to have a stimulatory effect on the adhesion process. Staining of the conidia with Coomassie Brilliant Blue revealed strong labelling of the layer covering the adhesive bud (Fig. 1d). This proteinaceous layer was removed after Pronase E treatment. 

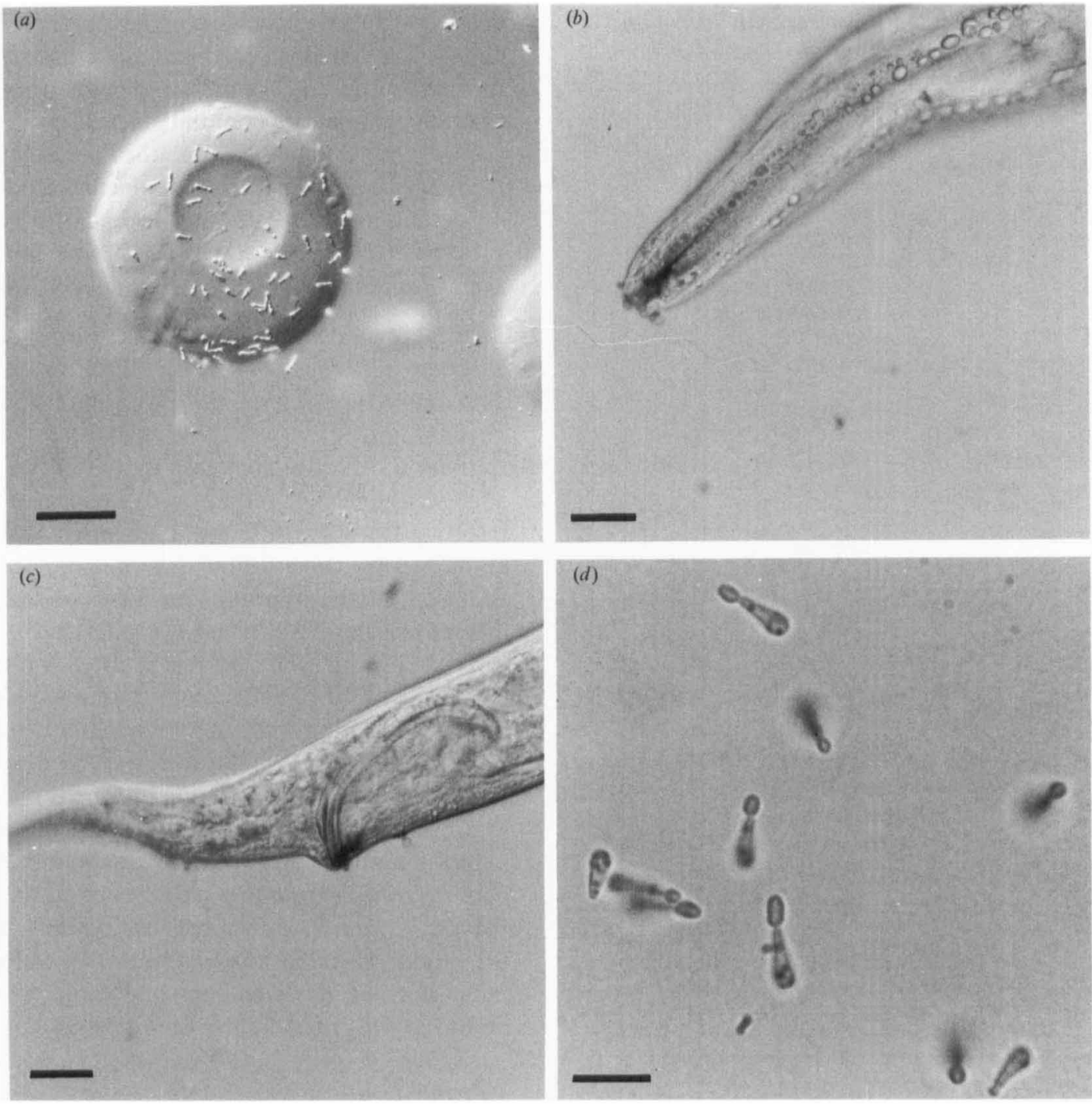

Fig. 1. (a) Attachment of $D$. coniospora conidia to positively charged ion-exchange beads. Bar, $25 \mu \mathrm{m}$. (b) Sensory organs at the head of $P$. redivivus and their exudates stained with the protein stain Coomassie Brilliant Blue G-250. Bar, $10 \mu \mathrm{m}$. (c) Sensory organs at the tail of $P$. redivivus and their exudates stained with Coomassie Brilliant Blue G-250. Bar, $10 \mu \mathrm{m}$. (d) Adhesive layer of the adhesive bud of the conidia of $D$. coniospora stained with Coomassie Brilliant Blue G-250. Bar, $5 \mu \mathrm{m}$.

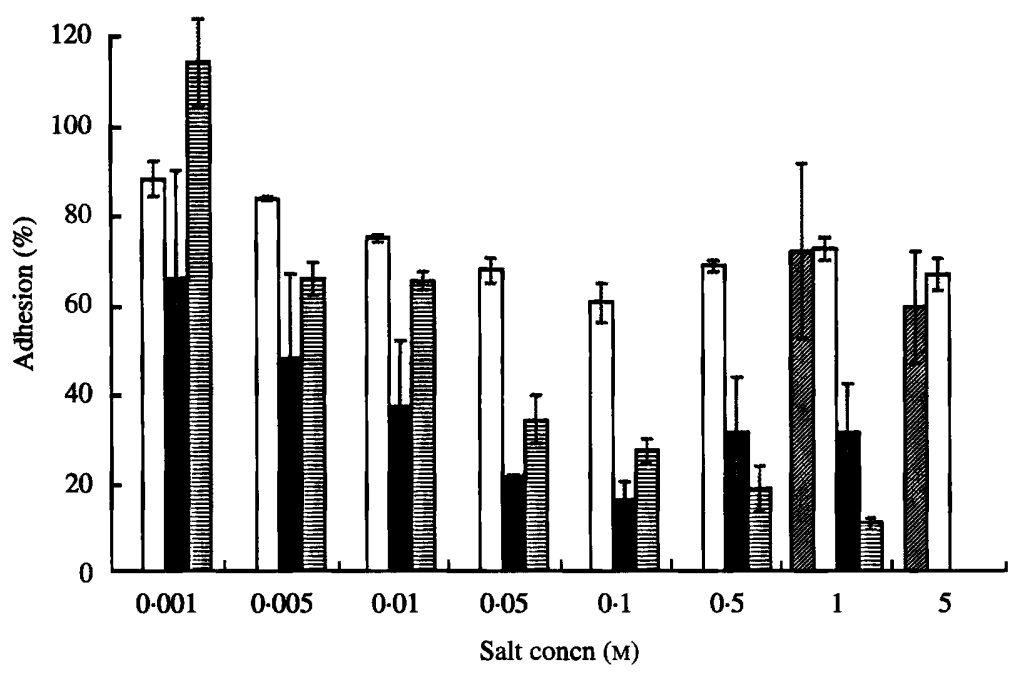

Fig. 2. Effects on adhesion of $D$. coniospora conidia to the nematode $P$. redivivus after treatment of the conidia with different salts. All values are expressed as percentages of the controls $(100 \%)$. 圆, $\mathrm{LiCl} ; \square, \mathrm{NaCl} ; \square, \mathrm{MgSO}_{4}$; 是, $\mathrm{CaCl}_{2}$. Vertical bars represent $\mathrm{SE}$ values. 
Table 3. Effects of enzyme treatment of $P$. redivivus on adhesion of $D$. coniospora conidia

\begin{tabular}{|c|c|c|c|}
\hline \multirow[b]{2}{*}{ Enzyme } & \multicolumn{2}{|c|}{ Mean $^{*} \pm \operatorname{SE}(n)$} & \multirow[b]{2}{*}{$P+$} \\
\hline & Active enzyme & Denatured enzyme & \\
\hline Pronase E & $27 \cdot 4 \pm 9 \cdot 3(2)$ & $83.5 \pm 0.5(2)$ & $P<0.05$ \\
\hline$\beta$-Galactosidase & $74.9 \pm 7.5(2)$ & $69 \cdot 9 \pm 33 \cdot 1(2)$ & NS \\
\hline Lipase & $69 \cdot 1 \pm 10 \cdot 0(3)$ & $74 \cdot 7 \pm 7 \cdot 2(3)$ & NS \\
\hline$\beta$-Glucuronidase & $93.4 \pm 8.6(2)$ & $95 \cdot 6 \pm 3 \cdot 2(2)$ & NS \\
\hline L-Fucose dehydrogenase & $92 \cdot 6 \pm 8.5(2)$ & $104 \cdot 4 \pm 5 \cdot 6(2)$ & NS \\
\hline L-Amino acid oxidase & $87.9 \pm 13.2(2)$ & $122 \cdot 9 \pm 8 \cdot 1(2)$ & NS \\
\hline L-Lysine decarboxylase & $65 \cdot 2 \pm 14 \cdot 9$ & $67 \cdot 7 \pm 1.4(3)$ & NS \\
\hline$\beta$-Glucosidase & $93.5 \pm 9.8(2)$ & $93.0 \pm 1.6(2)$ & NS \\
\hline$\alpha$-Glucosidase & $97 \cdot 1 \pm 9 \cdot 1(2)$ & $115 \cdot 1 \pm 5 \cdot 9(2)$ & NS \\
\hline Collagenase & $71.5 \pm 9 \cdot 5(3)$ & $80 \cdot 2 \pm 13 \cdot 4(3)$ & NS \\
\hline Neuraminidase & $93.4 \pm 7.8(3)$ & $76 \cdot 5 \pm 21 \cdot 1(3)$ & NS \\
\hline$\alpha$-Mannosidase & $78 \cdot 6 \pm 14 \cdot 0(6)$ & $93 \cdot 4 \pm 12 \cdot 5(6)$ & NS \\
\hline Endoglycosidase $F$ & $89 \cdot 8 \pm 2 \cdot 6(4)$ & $98 \cdot 8 \pm 5 \cdot 5(4)$ & NS \\
\hline Trypsin & $70 \cdot 5 \pm 2 \cdot 5(4)$ & $116 \cdot 2 \pm 1 \cdot 1(4)$ & $0.01<P<0.05$ \\
\hline
\end{tabular}

* Fraction of nematodes with adhering conidia in percentage of controls $(100 \%)$.

$\dagger t$-Test, difference between active and denatured enzymes.

NS, Not significant.

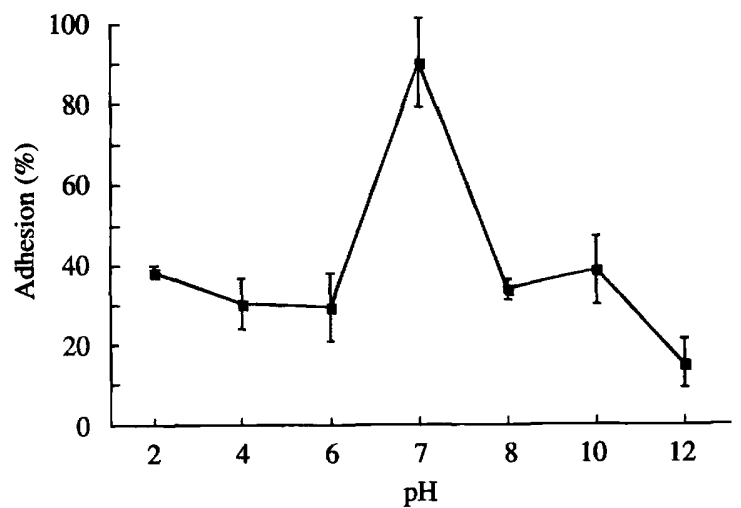

Fig. 3. Effects on adhesion of $D$. coniospora conidia to the nematode $P$. redivivus after treatment of the conidia with $10 \mathrm{~mm}$-Universal buffer solution. All values are percentages of controls (100\%). Vertical bars represent $\mathrm{SE}$ values.

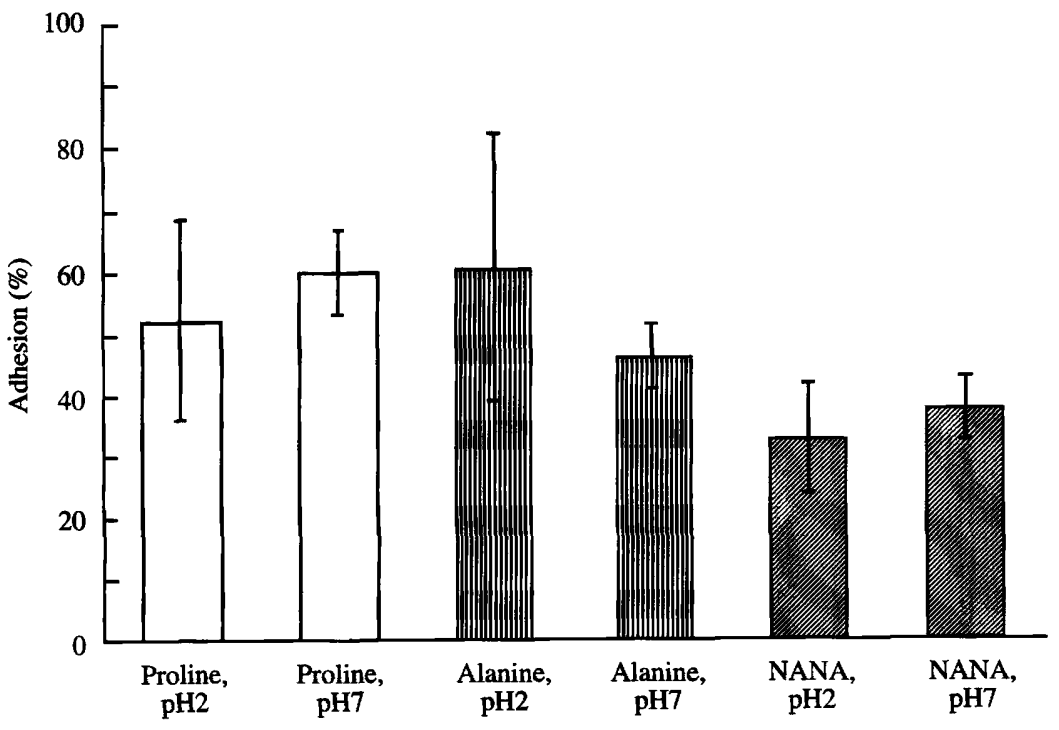

The nematodes treated with the proteolytic enzymes (and the other enzymes) remained alive and after 3-4 d the nematodes became infected, probably when new exudates had accumulated due to a constant production of the material. Similar effects were observed with the conidia, but in this case adhesive buds may have been formed after maturation of younger conidia. Furthermore, conidia adhering to the nematodes could be detached after Pronase E treatment by vortexing, which was not possible with control specimens.

\section{Discussion}

The conidia of $D$. coniospora adhered to all nematode species tested. Thus, there appears to be little host
Fig. 4. Effects on adhesion of $D$. coniospora conidia to the nematode $P$. redivivus after treatment of the conidia with alanine, proline or $\mathrm{N}$ acetylneuraminic acid (NANA) at $\mathrm{pH} 2$ and $\mathrm{pH} 7$. All values are percentages of controls $(100 \%)$. Vertical bars represent SE values. 
Table 4. Effects of enzyme treatment of D. coniospora conidia on adhesion to $P$. redivivus

\begin{tabular}{|c|c|c|c|}
\hline \multirow[b]{2}{*}{ Enzyme } & \multicolumn{2}{|c|}{ Mean* \pm SE $(n)$} & \multirow[b]{2}{*}{$P \dagger$} \\
\hline & Active enzyme & Denatured enzyme & \\
\hline Pronase E & $4 \cdot 5 \pm 2 \cdot 5(2)$ & $69 \cdot 7 \pm 12 \cdot 2(2)$ & $0.01<P<0.05$ \\
\hline$\beta$-Galactosidase & $115 \cdot 0 \pm 8.0(2)$ & $88.2 \pm 18.9(2)$ & NS \\
\hline Lipase & $83.0 \pm 1.0(2)$ & $86.6 \pm 2 \cdot 3(2)$ & NS \\
\hline$\beta$-Glucuronidase & $88 \cdot 9 \pm 15 \cdot 1(2)$ & $106 \cdot 3 \pm 7.8(2)$ & NS \\
\hline L-Fucose dehydrogenase & $102 \cdot 5 \pm 22 \cdot 5(2)$ & $120 \cdot 0 \pm 2 \cdot 0(2)$ & NS \\
\hline L-Amino acid oxidase & $82 \cdot 6 \pm 5 \cdot 3(2)$ & $91 \cdot 6 \pm 14 \cdot 8(2)$ & NS \\
\hline L-Lysine decarboxylase & $90.7 \pm 9.3(2)$ & $89.7 \pm 5.0(2)$ & NS \\
\hline$\beta$-Glucosidase & $113 \cdot 8 \pm 41 \cdot 2(2)$ & $71 \cdot 0 \pm 7 \cdot 2(2)$ & NS \\
\hline$\alpha$-Glucosidase & $82.8 \pm 15.6(2)$ & $95 \cdot 0 \pm 21.0(2)$ & NS \\
\hline Collagenase & $92.3 \pm 1.7(2)$ & $82 \cdot 7 \pm 9 \cdot 5(2)$ & NS \\
\hline Neuraminidase & $99.5 \pm 18.0(3)$ & $101.5 \pm 8.7(3)$ & NS \\
\hline$\alpha$-Mannosidase & $145 \cdot 0 \pm 10 \cdot 6(6)$ & $135.7 \pm 6.4(6)$ & NS \\
\hline Endoglycosidase $\mathrm{F}$ & $26.5 \pm 2.6(4)$ & $21 \cdot 9 \pm 4.4(4)$ & NS \\
\hline Trypsin & $20 \cdot 1 \pm 9 \cdot 5(4)$ & $10 \cdot 1 \pm 5 \cdot 4(4)$ & NS \\
\hline
\end{tabular}

* Fraction of nematodes with adhering conidia in percentage of controls $(100 \%)$. $\dagger t$-Test, difference between active and denatured enzymes. Ns, Not significant.

specificity involved in conidial adhesion. In a previous study (Jansson et al., 1985) it was observed that, of 17 nematode species tested, the conidia of $D$. coniospora adhered to all but two plant-parasitic nematodes, Xiphinema americanum and Bursaphelenchus xylophilus. In the present study, as in the previous one, the conidia adhered to bacteriovorous, plant-parasitic as well as animal-parasitic nematodes. It has prevously been observed that adhering conidia do not necessarily penetrate and infect the nematodes (Jansson et al., 1985, 1987). In the current study only two nematode species became infected, $P$. redivivus and $D$. dipsaci. Interestingly, the closely related species $D$. dipsaci and $D$. destructor showed a different response in that $D$. destructor was not infected indicating a missing interaction signal. It seems probable, from these observations, that the infection process involves at least two stages which are dependent on the chemical make-up of the attachment sites of the nematode surface. The first stage involves the signal for adhesion, which appears to be common among most nematodes and specific in the sense that the adhesion generally takes place only at the chemosensory organs of the nematode. The second stage involves the initiation of the penetration process, involving both enzymic and mechanical processes, as suggested by Dijksterhuis et al. (1990). A second signal may be necessary to induce these processes in the fungus.

The hypothesis suggesting the presence of a sialic-acidspecific lectin on the conidia of $D$. coniospora binding to sialic residues on the nematode (Jansson \& NordbringHertz, 1983, 1984) may be incorrect, since no sialic acids were found on the nematode $P$. redivivus (Bacic et al.,
1990; Reuter et al., 1991). Evidence for the involvement of sialic-acid-specific lectin was based mainly on (i) inhibition of conidial adhesion after sialic acid treatment ( $>65 \%$ inhibition), (ii) inhibition of adhesion after treatment of conidia with trypsin and glutaraldehyde (about 50\%), and (iii) a 10-20\% reduction of adhesion after treatment of the nematodes with neuraminidase or the sialic-acid-specific lectin limulin. In the present investigation, using a new isolate of $D$. coniospora, $N$ acetylneuraminic acid was the only carbohydrate tested which inhibited adhesion of conidia. Proline and alanine reduced adhesion of the conidia to the same extent as $\mathrm{N}$ acetylneuraminic acid. The sialic acid contains carboxyland amino groups, and if these are important for the adhesion process similar effects would also be obtained with amino acids. Treatment of the conidia with proteases reduced adhesion as in the previous investigation and indicates the importance of proteinaceous materials on the conidia for attachment. Treatment of the nematodes with neuraminidase had no effect on adhesion as seen in the earlier studies (Jansson \& Nordbring-Hertz, 1983, 1984). This variation may have been due to the fact that neuraminidases often contain proteases and other glycosidases that may interfere with the results (Schauer, 1982). The neuraminidase used in this study contained $<0.001$ units protease $\mathrm{mg}^{-1}$. Previous enzyme preparations contained unknown amounts of protease which may have affected adhesion. The effect of limulin was not tested in this investigation, but it is possible that the previous results (Jansson \& NordbringHertz, 1984) may have been due to nonspecific effects of the glycoprotein of this lectin, similar to the effects of 
some of the denatured enzymes in the current study. Thus, it is probable that the results obtained earlier are due to a different mechanism from the one suggested.

The present investigation supports the view that proteinaceous materials surrounding the adhesive buds of the conidia are involved in the adhesion to the nematodes. The material exuded from the sensory structures of the nematodes also seems to be involved. Six glycosidases hydrolysing terminal carbohydrates and one endoglycosidase failed to reveal any binding to carbohydrate moieties both on the conidia and the nematodes. The adhesive produced by the zoosporic nematophagous fungus Catenaria anguillulae also appears to be proteinaceous without carbohydrate moieties (Tunlid et al., 1991 b). Proteins that have been reported to be involved in the adhesion of other parasitic fungi to their hosts apparently bind to a carbohydrate receptor (Nicholson \& Epstein, 1991). In contrast, this study supports a protein-protein interaction, since the enzyme experiments indicate no involvement of either carbohydrates or lipids. However, carbohydrates are known to exist on the conidia of $D$. coniospora as shown by the unspecific histochemical stain ruthenium red (Saikawa, 1982), and mannose, at least, has been reported on the tip of the head of $P$. redivivus (Jansson et al., 1986), but does not appear to be involved in the adhesion process.

The inhibition studies with $N$-acetylneuraminic acid and the amino acids indicate the involvement of carboxyl groups or amino groups. Possible binding to carboxyl groups was supported further by the observation that carboxylated polystyrene beads bound to the adhesive buds of the conidia. In order to study the involvement of hydrophobic interactions polystyrene microbeads were used. The binding of such beads to the entire surface of the conidia indicates that the bud and the spore surface are equally hydrophobic. Hydrophobic interactions are therefore unlikely to account for the specific binding of the conidial buds to nematodes. Furthermore, the lack of binding of the conidia by negatively charged ionexchange gels, and binding of positively charged beads to the whole conidial surface, suggests that electrical charge interactions are not involved in the adhesion process.

The effects of the lower and higher $\mathrm{pH}$ values on the adhesion process indicate that the protein molecules in the adhesive coating of the conidial buds are sensitive to even small variations in $\mathrm{pH}$. Similar effects were obtained with both unbuffered solution ( $\mathrm{pH}$ 2-12 adjusted with $\mathrm{NaOH}$ or $\mathrm{HCl}$ ) or with citrate buffer, $\mathrm{pH} 3-7 \cdot 5$ (data not shown).

The results of the inhibition tests with the different salt solutions indicate that the adhesion system is not extremely sensitive to high ionic strength. It is striking that treatment of the conidia with $5 \mathrm{M}-\mathrm{LiCl}$ and $-\mathrm{NaCl}$ had no effect on adhesion. $\mathrm{LiCl}$ at $4-5 \mathrm{M}$ has been used to extract surface proteins of fungi (Teepe et al., 1988) and shown to reduce the adhesion of nematodes to the nematode-trapping fungus Arthrobotrys oligospora (Tunlid et al., 1991 a). With D. coniospora, treatment of the conidia with $\mathrm{LiCl}$ had no effect, suggesting a difference in the properties of the adhesins involved. Morphological differences between the adhesins of the two fungi can also be observed using transmission electron microscopy. The polymeric material of $A$. oligospora changes from an amorphous to a fibrillar structure after nematode contact, whereas the material from $D$. coniospora remains fibrillar throughout the entire infection process (Jansson \& Nordbring-Hertz, 1988; Veenhuis et al., 1985; Dijksterhuis et al., 1990; Tunlid et al., 1992).

In conclusion, it seems that the adhesion of $D$. coniospora conidia to nematodes is a specific process in the sense that the conidia generally attach only to the sensory structures of the nematodes, irrespective of fungal strain or nematode species. The adhesion appears to involve a protein on the adhesive bud of the conidia and a protein deriving from the exudates of the sensory organs of the nematode. Involvement of carbohydrates or other molecules could not be shown in the present investigation, but cannot be excluded. Carboxyl groups may take part in the interaction as suggested by some tests. A second stage of host specificity involves a signal for initiation of the penetration process which appears to be more specific resulting in infection of only a few nematode species. It is possible that this (chemical) signal comes from the exudates of the sensory organs which may vary between nematode species.

Skilful technical assistance of Agneta Persson and Lena Thiman is greatly acknowledged. I wish to thank Dr K. Bengt Eriksson, Swedish University of Agricultural Sciences, Ultuna, Sweden; Dr Trude Hard, Institut für Wissenschaftlichen Film, Göttingen, Germany; Dr Peter Nansen, Royal Veterinary and Agricultural University, Frederiksberg, Denmark; Dr Thierry Vrain, Agriculture Canada, Vancouver, Canada; and Dr Urs Wyss, University of Kiel, Kiel, Germany for supplying fungal strains and nematode cultures. This work was supported by grants from the Swedish Natural Science Research Council.

\section{References}

Bacic, A., Kahane, I. \& Zuckerman, B. M. (1990). Panagrellus redivivus and Caenorhabditis elegans: evidence for the absence of sialic acids. Experimental Parasitology 71, 483-488.

DiJksterhuIS, J., VeENhUIS, M. \& HARDER, W. (1990). Ultrastructural study of the adhesion and initial stages of infection of nematodes by conidiospores of Drechmeria coniospora. Mycological Research 94, $1-8$.

HAZEN, K. C. \& HAZEN, B. W. (1987). A polystyrene microsphere assay for detecting surface hydrophobicity variations within Candida albicans populations. Journal of Microbiological Methods 6, 289-299.

JANSSON, H.-B. \& NordBring-HerTZ, B. (1979). Attraction of nematodes to living mycelium of nematophagous fungi. Journal of General Microbiology 112, 89-93.

JANSSON, H.-B. \& NORDbrInG-HeRTZ, B. (1983). The endoparasitic 
nematophagous fungus Meria coniospora infects nematodes specifically at the chemosensory organs. Journal of General Microbiology 129, 1121-1126.

JANSSON, H.-B. \& NORDBRING-HeRTZ, B. (1984). Involvement of sialic acid in nematode chemotaxis and infection by an endoparasitic nematophagous fungus. Journal of General Microbiology 130, 39-43.

JANSSON, H.-B. \& NORDBRING-HERTZ, B. (1988). Infection events in the fungus-nematode system. In Diseases of Nematodes, vol. II, pp. 59-72. Edited by G. O. Poinar, Jr \& H.-B. Jansson. Boca Raton: CRC Press.

Jansson, H.-B., von Hofsten, A. \& von Mecklendurg, C. (1984). Life cycle of the endoparasitic fungus Meria coniospora: a light and electron microscopic study. Antonie van Leeuwenhoek 50, 312-327.

JANSSON, H.-B., JEYAPRAKASH, A. \& ZUCKERMAN, B. M. (1985). Differential adhesion and infection of nematodes by the endoparasitic fungus Meria coniospora (Deuteromycetes). Applied and Environmental Microbiology 46, 552-555.

Jansson, H.-B., Jeyaprakash, A., Coles, G. C., Marban-Mendoza, N. \& ZuCKeRMAN, B. M. (1986). Fluorescent and ferritin labelling of cuticle surface carbohydrates of Caenorhabditis elegans and Panagrellus redivivus. Journal of Nematology 18, 570-574.

Jansson, H.-B., Dackman, C. \& ZuCKerman, B. M. (1987). Adhesion and infection of plant parasitic nematodes by the fungus Drechmeria coniospora. Nematologica 33, 480-487.

Nicholson, R. L. \& Epstein, L. (1991). Adhesion of fungi to the plant surface. In The Fungal Spore and Disease Initiation in Plants and Animals, pp. 3-23. Edited by G. T. Cole \& H. C. Hoch. New York: Plenum Press.

Pendland, J. C. \& Boucias, D. G. (1991). Physiochemical properties of cell surfaces from the different developmental stages of the entomopathogenic hyphomycete Nomureae rileyi. Mycologia 83, 264-272.
Perrin, D. D. \& Dempsey, B. (1974). Buffers for $p H$ and Metal Ion Control. London: Chapman and Hall.

Premachandran, D., von Mende, N., Hussey, R. S. \& McClure, M. A. (1988). A method for staining nematode secretions and structures. Journal of Nematology 20, 70-78.

Reuter, G., Aumann, J., Wyss, U., Jansson, H.-B. \& Schauer, R. (1991). Panagrellus redivivus: Failure to find evidence for the occurrence and biosynthesis of sialic acids. Experimental Parasito$\log y$ 73, 389-395.

SCHAUER, R. (1982). Chemistry, metabolism, and biological functions of sialic acids. Advances in Carbohydrate Chemistry and Biochemistry 40, 131-234.

SaIKaWA, M. (1982). An electron microscope study of Meria coniospora, an endozoic nematophagous Hyphomycete. Canadian Journal of Botany 60, 2019-2023.

TEEPE, H., BötTGE, J.-A. \& WöstemeYER, J. (1988). Isolation and electrophoretic analysis of surface proteins of the zygomycete Absidia glauca. FEBS Letters 234, 100-106.

Tunlid, A., Johansson, T. \& NoRdBring-HeRTZ, B. (1991 $a$ ). Surface polymers of the nematode-trapping fungus Arthrobotrys oligospora. Journal of General Microbiology 137, 1231-1240.

Tunlid, A., Nivens, D. E., Jansson, H.-B. \& White, D. C. (1991b). Infrared monitoring of the adhesion of Catenaria anguillulae zoospores to solid surfaces. Experimental Mycology 15, 206-214.

Tunlid, A., Jansson, H.-B. \& NordBring-HerTz, B. (1992). Fungal attachment to nematodes. Mycological Research 96, 401-412.

VeEnhuts, M., Nordbring-Hertz, B. \& Harder, W. (1985). An electron microscopical analysis of capture and initial stages of penetration of nematodes by Arthrobotrys oligospora. Antonie van Leeuwenhoek 51, 385-398.

Zuckerman, B. M., Dicklow, M. B., Coles, G. C. \& MarbanMendozA, N. (1989). Loss of virulence of the endoparasitic fungus Drechmeria coniospora in culture. Journal of Nematology 21, 135-137. 